\title{
Investigation and research on public toilets in classical gardens of Suzhou
}

\author{
Ling $\mathrm{Xu}$, Chunxiang Cao
}

Suzhou Institute of Trade and Commerce, Suzhou 215009, China

Keywords: Suzhou; Classical gardens; Public toilets; Toilet culture

\begin{abstract}
As tourism of Suzhou develops, an increasing number of tourists are attracted by classical gardens of Suzhou and infrastructures in such gardens are also constructed continuously. Especially, with respect to public toilets in gardens, Administrative Office of Gardens pays attention to managing public toilets and works hard to make tourists to have a perfect impression on gardens when facilities and equipment develop towards automation. However, unbalanced development also exists. In another word, construction of famous gardens with a large passenger flow volume has been improved, while level of tourism toilets in unknown gardens with an ordinary passenger flow volume is still backward. Besides, Administrative Office of Gardens has not included environmental protection in schedules and personalized configuration is little in public toilets of gardens. Comprehension and importance attached to toilet culture are not enough. There is a large gap between China and developed countries. The author hopes to put forward some improvement measures by investigating and studying public toilets in classical gardens of Suzhou. According to investigation on public toilets in classical gardens in Suzhou, it is found that both construction and management of public toilets in several gardens with high popularity have become perfect, while basic situations of public toilets in gardens with a small passenger flow volume are worrying. In addition, Administrative Office of Gardens in Suzhou neither pays enough attention to environmental problems about public toilets nor publicizes and popularizes toilet culture. Then, some uncivilized toileting behaviors appear in tourists, which causes much inconvenience for cleaners to clean such public toilets. Compared with developed countries, Suzhou falls behind largely in these aspects. The author finds that advantages and disadvantages of public toilets in gardens by investigating and studying layout, building features, basic facilities and equipment, sanitation and hygiene as well as construction and management of public toilets in gardens of Suzhou. Additionally, the author tries to propose improvement measures by analyzing and consulting construction and management measures about tourism public toilets in other countries and regions.
\end{abstract}

\section{Status analysis of public toilets in classical gardens of Suzhou}

Classical gardens of Suzhou occupy most of tourism resources in Suzhou. Up to now, about over 160 gardens have been opened to the public and the number of their visitors has grown step by step. Besides, as a famous garden city in the world, Suzhou attracts a number of overseas tourists to go sightseeing. Tourism toilets have run through tourism development and situations of public toilets in gardens will also have influence on tourists' impression about classical gardens of Suzhou and then generate wider negative impacts.

1.1 Layout and building features of public toilets

1.1.1 Layout

1) Traditional opinions begin to be changed. In the past, many places treat tourism toilets as unpresentable parts and avoid such sites that people must need as much as possible. Nowadays, construction of public toilets has drawn attention of Administrative Office of Gardens in Suzhou.

2) Distribution of public toilets in most gardens is arranged according to layout of gardens themselves and their configuration is reasonable. For instance, Humble Administrator's Garden is divided into three parts and sets up a public toilet in the north of exit to its eastern garden, in the north of Jianshan Building of its central garden and in Penjing Garden of its western garden, 
respectively. Finally, it builds a public toilet behind the tea house near the entrance. Such toilets are distributed reasonably, so tourists can find them easily and be distributed well. Public toilets in most gardens are courtyards, which are separated from scenic spots and can also be found by tourists.

1.1.2 Building features

1) Reflect garden styles and integrate with garden architecture. Most public toilets in gardens are formed by reconstructing old buildings. They are made of grey tiles and white walls, which is consistent with color of a whole garden and shows elegance and simplicity.

2) They are mainly independent courtyards and have good tacitness. Besides, there is enough space to beautify environment of public toilets. Take Guanyun Peak Toilet in Lingering Garden for example. A square door leaps to eyes firstly, above which there is a square brick being carved with the two words 'Public Toilet'. After entering the door, we may see a half-round stone table and two stone chairs. There are some flowers and trees in the small flower nursery. A large mirror is inlaid outside the toilet, which enlarges visual space largely.

3) Decoration integrating Chinese and western styles. Advanced devices can be found inside toilets, while some decorations with classical features of China will be added appropriately. For instance, landscape paintings about gardens are hung on walls of Lingering Garden and Humble Administrator's Garden. Retiring rooms are also built outside public toilets of Humble Administrator's Garden and interior furniture is Ming-style furniture. This can coordinate with landscape, integrate public toilets having western advanced facilities with classical gardens well and avoid in inconformity.

1.2 Facilities and equipment

Squatting pans in public toilets of gardens adopt auto-induction and water faucets and dryers are also automatic nowadays. On the one hand, this can reduce waste of water resources effective and prevent some tourists from making sanitation worse because of insufficient consciousness; on the other hand, tourists get more convenience and grade of public toilets is improved continuously. Besides, most public toilets are equipped with humanized facilities and dedicated toilets for the disabled. Additionally, one handrail is built near each squatting pan, a foldable table where babies can be placed is inlaid in walls and chairs are provided in front of wash basins so that tourist can take a rest in Humble Administrator's Garden.

1.3 Sanitation and hygiene

Cleaners are assigned to all pubic toilets in gardens to clean squatting pans, pools, walls, windows and mullions. All visible places must be clean and the number of times when cleaning is done is irregular. There is only one requirement, i.e., toilets must be clean at any time. All public toilets are undertaken by property management companies that require toilets must be clean at any moment and will ask specially-assigned people to check sanitation. Lingering Garden carries out tracking system, i.e., toilets will be cleaned once a batch of tourists leave and specially-assigned people check sanitation every day.

1.4 Environmental protection about facilities and equipment

Although basic facilities and equipment and sanitation of public toilets in gardens of Suzhou have been improved largely, there are no environmental toilets in such gardens, let alone new science and technology or emphasis on humanistic spirit in tourism toilets of countries with developed tourism. It can be said that all toilets in existing classical toilets of Suzhou utilize water filling type, which not only brings high funding pressure on management agencies but also pollutes neighboring water. Up to now, Suzhou has been a city lacking water resources, which has been an indisputable fact. The number of visitors who go sightseeing in gardens of Suzhou reaches up to several thousand and even above ten thousand during peak seasons, which forms a higher burden.

\section{Problems existing in public toilets in classical gardens of Suzhou}

2.1 Toilet culture is lacked compared with tourism public toilets in countries with developed tourism

Toilets represent a culture and reflect human civilization. Developed countries pay much attention to generation and cultivation of 'toilet culture'. For instance, computer toilets appear in 
France, where toilet newspapers are issued. Japan holds 'National Day of Public Toilets' once a year, and senators work on the spot personally at that moment. Countries like America and Singapore elect 'famous toilets' regularly. Attention from all sectors of society lays a solid ideological foundation for construction of tourism toilets. In the contemporary era, countries with developed tourism value construction and management of tourism toilets very much, multi-functionalize such toilets, use new technology widely to make toilets have environmental functions to a larger extent and pay much attention to humanization design. All of these are the weakest links of gardens in Suzhou. Public toilets in classical gardens in Suzhou only keep providing convenient and comfortable toileting environment for tourists and fail to realize toilets represent a culture completely. In addition, it seems that tourists do not have such consciousness. This situation is caused by overall environment in China. There is a large gap between China and foreign countries in the aspect of the degree to which they value toilet culture.

2.2 Humanized facilities in public toilets in classical gardens of Suzhou are incomplete

Facilities in public toilets in classical gardens of Suzhou walk towards automation and Suzhou realizes configuration of humanized facilities. Squatting pans for the disabled are configured for each public. However, only Humble Administrator's Garden realizes that squatting pans for the disabled should be built in the first position and other gardens built the squatting pan for the disabled in the last position. Additionally, Humble Administrator's Garden establishes platforms where babies may be placed and installs telephones. It can be said that Humble Administrator's Garden has been considerate. Nevertheless, platforms where babies may be placed and telephones do not have much practicability. Since tourists do not realize convenience brought by these things, they will not use them.

\subsection{Construction level of public toilets is related to popularity of gardens}

When we investigate public toilets in classical gardens of Suzhou, we find that gardens with high popularity, such as Humble Administrator's Garden and Lingering Garden with a large passenger flow volume every day, facilities of public toilets in such gardens are quite advanced and management is strict. However, when we investigate small gardens with low popularity, such as Couple's Garden of Retreat and Joyous Garden, it is found that both their facilities and management are backward and the number of toilets in such gardens is controlled to be 1-2 only.

\section{Measures used to perfect construction of tourism toilets in classical gardens of Suzhou}

\subsection{Enhancing management system}

In the process in which administrative departments of gardens check sanitation in public toilets of gardens, they should adopt irregular inspection, especially, during rush hours when there are a large number of tourists. When necessary, questionnaires may be issued to tourists. In case of problems, corresponding improvement measures may be utilized. Activities which direct at rating public toilets may be held among gardens, which can not only strengthen cleaners' attention to sanitation in public toilets but also enable gardens to learn advantages of others and improve toileting environment. It is essential to pay attention to cultivating cleaners' consciousness of sanitation and hygiene and encourage them to propose precious opinions on construction of public toilets since they learn situations about public toilets most.

3.2 Constructing personalized toilets and promoting changes in opinions

Public toilets in gardens of Suzhou have satisfied people's demands for safety and comfort, but they lack personalized design and all toilets' keynote is gardens and their decoration is antique. If they can get rid of the stale and bring forth the fresh, they can not only increase their attraction but also adjust tourists' vision to prevent aesthetic fatigue and make tourists learn public toilets are not only places where they can answer a call of nature but also have their own culture and devote to changing traditional opinions of tourists. Considering this, gardens may hold exhibitions about design of public toilets in gardens. There have been a great many of famous toilet museums in the world up to now. It can be said that Garden Museum of is a great site for exhibition.

3.3 Enhancing funding and try to realize environmental functions as soon as possible

To realize environmental protection of public toilets, combination with high science and 
technology is required and professional talent must be introduced. Requirements for funds are high. However, this is quite beneficial from the perspective of long-term interests. Firstly, this can reduce Suzhou's burden in the aspect of water resource shortage. Secondly, gardens may realize sustainable development. In foreign countries, water closets have become 'a backward opinion which should be washed away long time ago'. With respect to solutions to funds, ticket price may be improved appropriately in addition to guidance funds input by the government and enterprises' sponsorship. Nevertheless, it is necessary to explain related reasons. When gardens attract tourists to visit and experience differences in environmental toilets, they should also strengthen publicity, cultivate tourists' consciousness that they should use public toilets in a civilized manner and deepen tourists' cognition about toilet culture.

\subsection{People first and reasonable design}

\subsubsection{Having details in mind and providing more considerate service}

Detail design of toilets can reflect care for people to the largest extent. For example, pothooks in toilets are quite important for tourists since they carry cameras and knapsacks generally. Without pothooks, it is rather inconvenient for them when they toilet. Pothooks are also provided by gardens in Suzhou, but they are usually installed at the top of a side, which is rather inconvenient. Gardens had better place them in the middle of the door which is in front of a squatting pan so that users can take their things easily. Meanwhile, it is essential to pay attention to maintenance about door locks in toilets. According to investigation, it is shown that tourists hate that door locks in toilets are damaged because this situation will make them feel unsafe and cause much inconvenience. Besides, hot water may be provided for tourists to wash their hands in winter, just like public toilets in KFC.

3.4.2 Showing concern for vulnerable groups and reflecting humanization

1) Establishing squatting pans for the old and the disabled

When tourism toilets are designed, this kind of squatting pans had better be built at the places that are near entrances to male and female toilets. However, these squatting pans are built in the last position in some classical gardens of Suzhou, which causes much inconvenience. Currently, only Humble Administrator's Garden builds a handrail near each squatting pan in every public toilet and Lingering Garden provides a special pool for people who cannot behave conveniently to wash their hands.

2) Facilities for infants

The number of tourists who travel with their babies increases, so tourism toilets should consider this when they are built. They had better build independent toilets for infants \& moms and a urinal for children and the distance from bottom of the urinal to the floor should not exceed $30 \mathrm{~cm}$.

3) 'Preferring girls to boys' highlight humanization

Design about tourism toilets cannot follow the principle that men and women are equal but changes towards the direction 'preferring girls to boys'. In accordance with investigation, it is found that the time taken by women to toilet is 130 seconds generally, which is three times longer than that of men. Thus, when squatting pans are designed, the number of squatting pans for women is larger or processing mode of Lingering Garden may be taken, i.e., when toilets are crowded, cleaners in the garden may open a male toilet for female tourists and supervise outside the male toilet for protection to make female tourists use toilets at east, which can not only save much space but also prevent resources from being wasted during tourist off-season.

4) Signs about toilets

Abandon WC and use 'Toilet'. Classical gardens of Suzhou have leaflets where distribution of such gardens is introduced and signs about toilets are expressed by 'WC'. WC is an indelicate expression, which is replaced with 'Resting Room' in foreign countries. Therefore, many foreign friends do not know 'WC'. Consequently, garden managers should pay attention to this aspect and not think this makes a fuss. Indeed, it relates 'face' of a garden and even a city. Translation about public notices and signs has relationship with overall quality of a city, so we hope administrative departments of gardens pay attention and use the uniform public sign 'Toilet' in English to give correct language environment and provide convenience for foreign tourists. 


\section{Reference}

[1] Zhang Shulin. Primary exploration on layout of tourism toilets [J]. Tourism Investigation, 2006(06).

[2] Zhong Hongmei. Thinking on development of tourism toilets at present [J]. Heihe Journal, 2004(01).

[3] Lin Yueying. Introduction to tourism environment protection [M]. Tourism Education Press, 2001(08).

[4] Sakamoto Nako. A collection of the best public toilets in the world [M]. Science Press, 2002.

[5] Li Guanghong. Analysis of new 'bottlenecks' in tourism development - tourism toilets [J]. Commercial Economy, 2006(10).

[6] Yu Senlin. 'Toilets' in English [J]. College English, 2002.

[7] Huang Ziyan. Discussion on construction of tourism toilets in China [J]. Journal of Zhejiang Wanli University, 2007(09).

[8] Li Wuling. Discussion on construction of tourism toilets in Sinkiang [J]. Eco-tourism Economy, 2007(07). 